\title{
O pensamento complexo de Edgar Morin como aporte epistemológico na formação docente
}

\author{
Líliam Maria Born Martineli* \\ Marilda Aparecida Behrens** \\ Edna Liz Prigol***
}

\section{Resumo}

O presente artigo apresenta os principais resultados dos estudos desenvolvidos pelo grupo de pesquisa PEFOP (Paradigmas Educacionais para a Formaçã)o de Professores) sob a luz dos pressupostos da Complexidade de Edgar Morin voltado para a formação docente. Adotou-se como problema de pesquisa: De que forma podemos inserir os construtos dos sete saberes, especificamente do saber da incerteza como base epistemológica para a prática pedagógica docente contribuindo com os desafios impostos para a educação na contemporaneidade? Como objetivo definiu-se: identificar as contribuições/construtos dos professores participantes do curso de formação docente on-line sobre os sete saberes de Morin (2000), com foco no quinto saber - ensinar a enfrentar as incertezas, como via de construção de uma prática pedagógica que atenda às demandas da educação da contemporaneidade. Trata-se de uma pesquisa de abordagem qualitativa, do tipo pesquisa-ação. Para a coleta de dados, via netnografia, foram utilizadas as produções dos participantes de um curso online a respeito da obra "Os Sete Saberes necessários para a Educação do Futuro, de Edgar

* Doutora em Educação pela PUC/PR. Professora no Unisantacruz - Centro Universitário Santa Cruz e FAEL - Faculdade Educacional da Lapa. liliammartinelli@hotmail.com

** Doutora em Educação pela PUC/SP. Professora do PPGE da PUC/PR Pontifícia Universidade Católica do Paraná. marildaab@gmail.com

*** Doutora em Educação pela PUC/PR. Professora da PUC/PR - Pontifícia Universidade Católica do Paraná, Curitiba. prigoledna@gmail.com 
Morin com destaque para o quinto saber- enfrentar a incerteza. Entre os principais resultados encontra-se o reconhecimento da necessidade de superar a ideia de certeza construída a partir da ciência clássica e a reconstrução reflexiva da prática pedagógica.

Palavras-chave: Formação Docente. Prática Pedagógica. Curso Online, Complexidade, Ensinar a Incerteza.

\section{Edgar Morin's complex thinking as an epistemo- logical support in teaching training}

\section{Abstract}

This article presents the main results of the studies developed by the research group PEFOP (Educational Paradigms for Teacher Education) in the light of the assumptions of Edgar Morin's Complexity focused on teacher education. It was adopted as a research problem: How can we insert the constructs of the seven knowledges, specifically the knowledge of uncertainty as an epistemological basis for the teaching pedagogical practice, contributing to the challenges imposed to education in contemporary times? The objective was defined: to identify the contributions / constructs of the teachers participating in the online teacher training course on Morin's seven knowledges (2000), focusing on the fifth knowing - teaching how to face uncertainties, as a way of building a pedagogical practice that meets the demands of contemporary education. It is a qualitative research, an action research type. For the collection of data, via netnography, the productions of the participants of an online course about the work "The Seven Knowledge Necessary for the Education of the Future", by Edgar Morin, with emphasis on the fifth knowledge- facing uncertainty, were used. Among the main results is the recognition of the need to overcome the idea of certainty built from classical science and the reflexive reconstruction of pedagogical practice.

Keywords: Teacher Education. Pedagogical Practice. Online Course, Complexity, Teaching Uncertainty.

\section{El pensamiento complejo de Edgar Morin como aporte epistemológico a la formación docente}

\section{Resumen}

El presente artículo presenta los principales resultados de los estudios desarrollados por el grupo de investigación PEFOP (Paradigmas Edu- 
cacionales para a Formación de Profesores) a la luz de los presupuestos de la Complejidad de Edgar Morin orientado a la formación docente. Se adoptó como problema de investigación: De que forma podemos introducir los constructos de los siete saberes, específicamente del saber da incertidumbres, como base epistemológica para la práctica pedagógica docente, contribuyendo a los desafíos impuestos para la educación en la contemporaneidad? Como objetivo se propone: identificar las contribuciones/constructos de los profesores participantes del curso de formación docente on-line sobre los siete saberes de Morin (2000), con enfoque en el quinto saber - enseñar para afrontar las incertidumbres, como vía de construcción de una práctica pedagógica que atienda las demandas de la educación en la contemporaneidad. Se trata de una investigación de enfoque cualitativo, del tipo investigación-acción. Para la recolección de datos, vía netnografia, fueron utilizadas las producciones de los participantes en un curso on-line sobre la obra "Los Siete Saberes Necesarios para la Educación del Futuro", de Edgar Morin, con enfoque en el quinto saber - afrontar la incertidumbre. Entre los principales resultados se encuentra el reconocimiento de la necesidad de superar la idea de certeza construida a partir de la ciencia clásica y la reconstrucción reflexiva de la práctica pedagógica.

Palabras-clave: Formación Docente. Práctica Pedagógica. Curso On-line, Complejidad, Enseñar la Incertidumbre.

\section{Introdução}

O século XX se mostrou como um tempo de grandes mudanças em todas as dimensões da vida que se organiza na biosfera do planeta Terra. Não se está falando apenas do ser humano, mas de todos os elementos que constituem o planeta. As mudanças não ocorrem sem motivo e, sem dúvida, o desenvolvimento da Ciência e, consequentemente, a geração da tecnologia estão entre os motivos geradores destas mudanças.

De forma objetiva e voltando o olhar para o ser humano pode-se afirmar que as ações humanas para a sua sobrevivência foram definidas e definiram a construção do conhecimento humano e o modo de viver em sociedade. Quando o ser humano entende que a sua razão poderia explicar o mundo e que para isso era necessário adotar procedimentos comuns de busca da verdade, nasce a ciência clássica que vem se consolidando desde o início do século 
XIX. Com foco no pensamento racional e objetivo consolidou-se uma visão da ciência que tem por base a experimentação, a medida, a separação, a certeza, a especialização, entre outras características (MORIN, 1999). O conhecimento só é válido se houver absoluta certeza e verdades inquestionáveis as quais poderiam garantir a sua aplicação a outras situações semelhantes no mundo das ciências.

Tais concepções pautaram a educação baseada na visão da razão que se desenvolveu por meio da busca de formas de organização e métodos que atendessem a reprodução do conhecimento. Essa visão cartesiana deu origem às diferentes tendências educacionais conservadoras, em especial, a abordagem tradicional e tecnicista, que se alternam ou se sucedem na história da humanidade.

Por outro lado, as mudanças vertiginosas ocorridas no decorrer do século XX trazem em si a inquietação a respeito da educação e suas contribuições para uma sociedade nova que emerge e se caracteriza pela rapidez das transformações e pela percepção de que nada é definitivo e tudo pode mudar de um instante para o outro. O início do século XXI, momento em que a tecnologia atinge expressão no cotidiano da sociedade, demanda por pensar a função da educação, de modo especial, para a formação do cidadão com competência para pensar o contexto presente, identificar os problemas e propor soluções. Mas, o século XXI vem requisitando novos construtos epistemológicos, filosóficos e pedagógicos, nos quais o aluno seja compreendido como um ser complexo resultante de múltiplas constituições: física, emocional, social, econômica, espiritual, biológica e química, entre outras. Para tanto, os docentes e estudantes precisam produzir o próprio conhecimento, a partir de contextualização e problematizações que se refiram a situações reais, atuando na investigação de maneira crítica, reflexiva e inovadora. O processo educativo numa visão complexa necessita considerar as múltiplas diferenças individuais evitando-se a padronização e a homogeneidade no relacionamento pedagógico.

Neste sentido, a presente pesquisa nasce a partir das inquietações e perguntas geradas no grupo de pesquisa Paradigmas Edu- 
cacionais e Formação de Professores - PEFOP, o qual desenvolve pesquisas iluminadas pelo pensamento complexo de Edgar Morin com foco na formação de professores. A efetivação desse processo de pesquisa manifesta-se no projeto, financiado pelo Conselho Nacional de Desenvolvimento Científico (CNPq), Paradigma da Complexidade, Transdisciplinaridade, como Pilares Epistemológicos para a Geração de Construtos, Saberes e Práticas na Formação Pedagógica dos Professores (PEFOP, 2020).

Entre as ações relativas a tal projeto está a oferta de um curso online para professores dispostos a compreender as contribuições do pensamento da complexidade de Edgar Morin, para a mudança da prática pedagógica a partir do estudo da obra, publicada em 2000, intitulada Os Sete Saberes necessários à Educação do Futuro. Pode-se dizer que a pesquisa é de abordagem qualitativa (BOGDAN, BIKLEN, 1999; FLICK, 2013), do tipo pesquisa-ação (THIOLLENT,2011) e tem como problema: De que forma podemos inserir os construtos dos sete saberes, especificamente do saber da incerteza como base epistemológica para a prática pedagógica docente contribuindo com os desafios impostos para a educação na contemporaneidade?

Sendo assim, foi estabelecido como objetivo identificar as contribuições/construtos dos professores participantes do curso de formação docente on-line sobre os sete saberes de Morin (2000), com foco no quinto saber - ensinar a enfrentar as incertezas, como via de construção de uma prática pedagógica que atenda às demandas da educação da contemporaneidade.

O desenvolvimento deste artigo compõe-se da apresentação dos elementos essenciais do pensamento complexo seguida da explanação do quinto saber - ensinar a enfrentar a incerteza. $\mathrm{Na}$ sequência são apresentados os dados coletados no decorrer da pesquisa-ação por meio do curso on-line e da análise das contribuições dos professores 


\section{Um olhar para o pensamento complexo de Edgar Morin}

O pensamento complexo apresentado por Edgar Morin vem sendo construído e sistematizado nos últimos 70 anos sendo muito conhecida, entre outras, a obra O Método, constituído por seis volumes (PENA-VEGA; ALMEIDA, PETRAGLIA, 2003). É importante destacar que o pensamento complexo teve como um de seus disparadores a busca pelas certezas defendidas pela ciência construída pelo rigor da aplicação do método científico. São as descobertas sobre a estrutura íntima da matéria, a luz e o calor responsáveis por revelar que a incerteza predomina no funcionamento da matéria que constitui o ambiente. (MORIN, 1999). Neste sentido, Nicolescu (1999) destaca que é no íntimo da ciência regida por princípios rigorosos de controle, da busca da ordem, da determinação, das certezas que ocorre a irrupção da percepção das relações sistêmicas cuja compreensão escapa ao olhar quantitativo característico da ciência clássica, visto que se caracterizam pelo dinamismo dos sistemas e a evidência da relação entre a ordem e a desordem . Desse modo, formam-se as brechas da microfísica e da macrofísica que geram a demanda por uma visão de mundo que ultrapasse a visão cartesiana sem excluí-la. (MORIN, 1990).

A constatação de que a realidade não pode ser reduzida ao simples indica que o modo de pensar reducionista e determinista tem importância, mas se mostra insuficiente para a compreensão profunda de um fenômeno. Por isso, tornou-se importante buscar um modo de pensar que admita e inclua a complexidade dos sistemas que compõem o viver. (MORIN, 1997).

Aprofundar o olhar sobre um fenômeno ou objeto implica compreender a organização de um sistema, e isso demanda considerar que ordem e desordem nutrem a manutenção de um sistema, pois se relacionam de muitas maneiras gerando o deslocamento do equilíbrio para pontos diversos e de forma constante. Ou seja, a realidade é caracterizada por movimentos diversos e constantes, em 
função da desestabilização da ordem por meio da desordem e a formação de uma nova ordem ou equilíbrio.

Diante disso, pode-se dizer que tanto a realidade como um todo quanto algum dos fenômenos que ocorrem dentro dela, podem ser entendidos como um todo cujas partes interagem continuamente, o que ocasiona mudanças nas partes e, consequentemente no todo. Neste sentido, Petraglia (2001, p. 28, grifo do autor) afirma que o "sistema deve ser considerado não só como uma unidade global, mas também como unitas multiplex, em que se associam termos antagonistas" (PETRAGLIA, 2001, p. 28, grifo do autor).

Tais ideias, destaca-se que pensar de modo complexo significa adotar um olhar que considere as diferentes dimensões do ser humano, o ambiente físico, a subjetividade do ser humano, a dinamicidade da realidade, entre outros, de modo a utilizar-se do conhecimento já produzido aliado à consciência de que o incerto, o aleatório faz parte da constituição da realidade. Desse modo, os limites impostos pela ciência clássica são transpostos sem que isso signifique torná-los insignificantes.

É evidente que, a partir dessa concepção, é inevitável questionar a educação e buscar novas possibilidades de pensamento e ação pedagógicas. Por isso, se fez necessário, dar atenção ao que Edgar Morin apresenta como saberes essenciais ao aprender e ensinar em tempos de grandes transformações.

\section{Tecendo conhecimentos sobre o saber e ensinar a incerteza}

Pensar a educação demanda por compreender alguns fatores importantes que definiram o contexto do final do século XX. A expansão da tecnologia inegavelmente impactou a comunicação no que se refere à velocidade com que as informações passaram a circular no mundo todo. Tornou-se normal acompanhar os fatos quase que ao vivo, pois “ "[...] o mundo chega diariamente e em caleidoscópio aos lares, [...]. Não há acontecimento, ocorrência, catástrofe que não sejam capturados por uma câmera e enviados a todos os 
horizontes [...]" (MORIN, 2001, p. 38). E isso transforma o modo de viver e leva a perceber que é preciso aprender a viver nesse contexto caracterizado pelo imediatismo, transformações constantes e interdependência econômica e cultural. Está consolidada a incerteza do ser e do viver.

Nesse movimento merece destaque o relatório da Comissão Internacional Sobre a Educação Para o Século XXI, coordenado por Delors (1996), apoiado pela UNESCO, que propõe os quatro pilares da educação: Aprender a ser, a fazer, a viver juntos e a conhecer, os quais indicam a necessidade de uma educação que se volte à totalidade do ser humano. E desse modo, a Unesco convida Edgar Morin a expor suas ideias a respeito da educação. A UNESCO reconhece também a proposição relevante de Morin (2000) na obra "Os Sete Saberes para a Educação do Futuro". A referida obra se pauta em saberes que necessitam ser desenvolvidos para ensinar nas escolas quando se pretende educar o ser humano para viver no contexto atual, ou seja, é preciso: 1) ensinar que ao produzir conhecimento são possíveis o erro e ilusão; 2) ensinar a escolher o conhecimento pertinente; 3) ensinar a condição humana; 4) ensinar a identidade terrena; 5) ensinar a enfrentar as incertezas; 6) ensinar a compreensão humana; 7) ensinar a ética do gênero humano.

Dentre os sete saberes trabalhados durante o curso online, optou-se por aprofundar nesse estudo o quinto saber proposto por Morin (2000): ensinar a enfrentar a incerteza. Sendo assim, pode-se buscar compreender a origem da preocupação de Morin com relação à incerteza. Neste sentido, é interessante observar que Morin (2000) inicia sua reflexão a respeito destacando algumas evidências da incerteza, entre elas: o modo como a história da humanidade acontece, pois implica nas relações entre a ordem e a desordem conduzindo a uma nova organização que não pode ser prevista com certeza, assim, não há como prever a ocorrência de guerras, catástrofes, entre outras; o universo ao invés de ser determinado, como explicava a ciência clássica, demonstrou que segue seu caminho por meio de ordens, desordens e nova organização sob os riscos dessas relações. 
Para enfrentar as incertezas Morin (2000) lembra que o caminho é incerto, mas pode render bons frutos quando sustentados pela compreensão de alguns princípios reveladores da presença da incerteza.

O cérebro humano em suas funções, por meio das ações do indivíduo, permite a tradução/reconstrução do real, mas isso significa que cada cérebro pode construir a sua tradução do real. Portanto, conhecer a realidade é totalmente incerto e, "isto nos mostra que é preciso saber interpretar a realidade antes de reconhecer onde está o realismo" (MORIN, 2000, p. 85). Assim, é preciso considerar que há algo invisível, não detectado ou então, resultado da falsa interpretação do real.

Dessa maneira, pode-se dizer que o ato de conhecer é incerto e o conhecimento produzido também, pois comporta "permanentemente, o risco de ilusão e de erro. [...] o conhecimento é a navegação em um oceano de incertezas, entre arquipélagos de certezas" (MORIN, 2000, p. 86)

A racionalidade aplicada à realidade resulta nas ações sobre ela. Tais ações resultam de "decisão, escolha, mas é também uma aposta. E na noção de aposta há a consciência do risco e da incerteza" (MORIN, 2000, p. 86). Desse modo, nem sempre a ação segue a sua intenção inicial. $\mathrm{O}$ seu curso pode ser desviado por fatores não percebidos ou imprevistos. A noção de ecologia da ação colabora com a compreensão desse processo, pois, "é, em suma, levar em consideração a complexidade que ela supõe, ou seja, o aleatório, acaso, inciativa, decisão, inesperado, imprevisto, consciência de derivas e transformações" (MORIN, 2000, p. 87). Ou seja, a ação humana comporta: arriscar e precaver, pois é na relação dialógica entre eles que ocorre o avanço; a percepção de que nem sempre os fins justificarão os meios, pois como "os meios e os fins inter-retroagem uns sobre os outros, é quase inevitável que meios sórdidos a serviço de fins nobres pervertam estes e terminem por substituí-los" (MORIN, 2000, p. 88), a possibilidade de perversão do seu sentido permitindo que seja destacado o seu efeito nefasto 
sufocando a inovação e arriscando perder o que já foi conquistado ( MORIN, 2000).

Por fim, há a incerteza psicológica, pois não é possível ter total consciência "do que se passa na maquinaria de nossa mente, [...]. Existe, portanto, a dificuldade do autoexame crítico, para o qual nossa sinceridade não é garantia de certeza, e existem limites para qualquer autoconhecimento" (MORIN, 2000, p. 85)

Sendo assim, é importante desenvolver o exercício de reconhecer os limites das certezas que comumente são alvo de busca e valorização pessoal e coletiva. Neste sentido Morin (2000, p. 90) indica que "a ecologia da ação convidá-nos, não à inação, mas ao desafio que reconhece seus riscos e às estratégias que permite modificar, até mesmo anular, a ação empreendida”.

Por outro lado, Morin indica que para o enfrentamento da dificuldade de lidar com as incertezas está o desenvolvimento do pensamento em que a estratégia seja o que norteia as ações, pois desse modo pode-se modificar a ação, repensar as escolhas, reconsiderar os riscos, abrir-se ao inesperado e agir com firmeza apesar dos riscos e das armadilhas promovidas pelo funcionamento do cérebro humano e do contexto em que está inserido.

\section{Metodologia}

Considerando o problema e o objetivo da presente pesquisa, percebe-se que sua origem está nos questionamentos a respeito das práticas pedagógicas desenvolvidas por professores e sua relação com a visão de mundo que possuem. Neste sentido, optou-se pela abordagem qualitativa do tipo pesquisa-ação, pois segundo Thiollent (2011, p. 20) trata-se de: “[...] base empírica que é concebida e realizada em estreita associação com uma ação ou com a resolução de um problema coletivo e no qual os pesquisadores e os participantes representativos da situação ou do problema estão envolvidos de modo cooperativo ou participativo".

A presente pesquisa nasce da realidade em que os pesquisadores e os participantes estão incluídos e buscam apresentar aspec- 
tos que possam contribuir para que a transformação constante da prática pedagógica de modo a tornar-se mais próxima das demandas de um tempo de incertezas.

A coleta de dados se deu de forma coletiva (THIOLLENT, 2011) por meio das reflexões desenvolvidas pelos participantes com a mediação dos pesquisadores em um curso online cujo foco estava no trabalho com a obra "Os Sete Saberes necessários para a Educação do Futuro", de Edgar Morin. A coleta de dados partiu da interação com os participantes por meio de um ambiente virtual, procedimento denominado netnografia (FERRO, 2015). Desse modo, pesquisador e participantes puderam trocar ideias de modo mais confortável tendo em vista que se utilizaram dos meios tecnológicos respeitando seus tempos e possibilidades.

Foram convidados a participar do curso on-line proposto "docentes que buscam ampliar sua visão de mundo, refletindo sobre a necessidade de reformar o pensamento quanto a prática pedagógica” (PEFOP, 2020). O início do curso contou com 45 professores participantes, porém no módulo "Enfrentar as incertezas", contou com as contribuições de 22 participantes, sendo essa a amostra para a presente pesquisa.

\section{O curso online sobre os sete saberes para a educa- ção do futuro}

O curso on-line "Formação de Professores para uma prática inovadora", foi proposto e preparado e implementado pelo grupo de pesquisa PEFOP-Paradigmas Educacionais para a Formação de Professores (2020), constituído por 23 pesquisadores, doutores, mestres, doutorandos e mestrandos, estudantes de graduação-PIBIC e colaboradores estrangeiros. Foi estabelecido como objetivo do curso "contribuir para a superação da visão conservadora, a qual propõe atividades descontextualizadas, fragmentadas, baseadas na repetição e reprodução de conteúdo". (PEFOP, 2020).

O referido curso teve início em 5 de março de 2018, estruturado em módulos que envolveram os sete saberes propostos por 
Edgar Morin (2000): (1) As cegueiras do conhecimento: erro e ilusão; (2) Princípios do conhecimento pertinente; (3) Ensinar a condição humana; (4) Ensinar a identidade terrena; (5) Enfrentar as incertezas; (6) Ensinar a compreensão e a (7) Ética do gênero humano. Cada módulo apresentou a seguinte estrutura:

i. Boas Vindas espaço organizado para o acolhimento do participante e apresentação do assunto principal; ii. Leitura do Estudo de Caso reservado para a apresentação de um caso envolvendo a temática em estudo; iii. Ponto de Partida espaço estruturado para incitar os participantes a apresentar suas primeiras impressões a respeito do assunto; iv. Estudo espaço contendo materiais de naturezas diversas incluindo um vídeo explicativo, um texto e um resumo em PPT do saber em estudo produzido pelo grupo de pesquisa, imagens e sugestões de links, e o capítulo do livro dos Sete Saberes; v. A Prática na Prática continha questões norteadoras, para que os participantes apresentassem suas aprendizagens ou percepções a respeito do estudo desenvolvido; vi. Pensamento Complexo na Prática Pedagógica, espaço para o participante relatar suas práticas e fazer a avaliação do módulo; viii. Referências contendo toda a bibliografia utilizada na montagem do módulo (PEFOP, 2000).

Utilizou-se da ferramenta fórum de discussão para promover debates entre os participantes, em cada uma das etapas dos módulos, esse espaço era mediado pelos pesquisadores do grupo PEFOP, de modo a estabelecer possibilidades de diálogo entre as partes envolvidas, tendo o cuidado de não deixar as participantes sem comentários a respeito das suas colocações e também de incentivar a participação com mensagens de motivação, via e-mail para a sua continuidade no curso e participação efetiva.

Nesse estudo, optou-se por apresentar as contribuições advindas do desenvolvimento do módulo 5 , relacionado ao saber ensinar a incerteza. Esse módulo foi realizado entre abril de 2018 e maio de 2018, e envolveu 22 participantes.

Tendo presente a dinamicidade da estrutura do módulo e a inserção de espaços para que os participantes expusessem suas ideias, considerou-se a fase: A Prática na Prática, como a fonte de 
dados que possibilitou reunir elementos para responder ao problema de pesquisa e atingir o objetivo proposto. A fase A Prática na Prática solicitou que os participantes elaborassem respostas para duas perguntas reflexivas, a saber:

1.Comente sobre algumas incertezas que você percebe no ambiente educacional, no que se referem as práticas pedagógicas presentes no século XXI.

2. De que forma podemos inserir este saber em nossa prática pedagógica, tornando o estudante apto a lidar com as incertezas que enfrentará ao longo de sua vida? (PEFOP, 2020).

Observou-se que todos os participantes integralizaram seus estudos nesse módulo e, com a finalidade de salvaguardar o anonimato, os participantes foram denominados com siglas de P.1 a P.22.

\section{Contribuições dos professores participantes}

Após a leitura do conjunto de dados obtidos, entendeu-se que seria possível organizá-los em algumas categorias que emergem tanto das produções dos participantes, quanto das perguntas reflexivas propostas. Desse modo, foram enfatizadas as seguintes categorias: mudanças locais e globais, reflexões sobre a prática pedagógica, professor contemporâneo, percepção sobre o aluno, contribuições para a reforma da prática pedagógica, as quais se justificam pelo fato de estarem presentes com frequência em momentos diferentes da produção dos participantes.

A categoria 'reflexões sobre a prática pedagógica' foi mencionada por 13 dos 22 participantes. As considerações apresentadas mostram a preocupação com relação ao modo de ver a educação, expressaram sobre a necessidade de superar concepções educacionais que não dão conta de responder aos desafios do mundo contemporâneo, e que consequentemente é refletida na prática pedagógica. Assim, os participantes evidenciaram a percepção das mudanças de contexto e os desafios que isso traz ao professor, como indicado a seguir:

[...] Hoje, durante a aula, o estudante tem ferramentas que permitem que 
ele questione, no ato, quem ensina. A globalização, a inclusão digital e o desenvolvimento sustentável cobram do educador questões complexas, e propor práticas pedagógicas que envolvam ações e projetos no tema sustentabilidade e relacionados a outras causas voltadas à melhoria do mundo, (P16)

[...]no presente momento, a incerteza também perpassa a prática dos educadores, que tentam lidar com o conflito de entender o quando as inovações ou permanências estão de fato agregando à formação dos estudantes. (P.22)

Por outro lado, os participantes destacam a importância de desenvolver práticas que priorizem a visão ampla do que é preciso aprender partindo da contextualização dos conteúdos sendo que para isso o professor precisa abrir-se ao novo e reinventar a sua prática, tais ideias são apresentadas a seguir:

[...] priorizar a aprendizagem a partir da contextualização dos conteúdos e disciplinas com a realidade e fazendo com que os estudantes busquem as diversas soluções para as situações e problemas apresentados. Acredito que esse seja realmente o caminho, pois não diria apenas que é preciso enfrentar as incertezas, mas é também necessário estar aberto às diversas soluções e caminhos que se evidenciam ao longo de um aprofundamento do conhecimento, concretizando assim uma visão mais ampla e global dos problemas da vida real.(P.4)

[...] Hoje, mais do que antes, emerge a necessidade de nos despirmos de todas as concepções tradicionais que temos da Escola e do Ensino. Hoje temos que reinventar estratégias e pensar o ato educativo como um momento em que professor, aluno e saber dialogam no mesmo espaço e em que nenhum destes pilares se sobrepõe aos outros. (P.1)

Desse modo, entende-se que os participantes reconheceram a presença da influência da incerteza no processo de ensinar e aprender e a necessidade de refletir sobre a prática desenvolvida bem como sobre a sua reconstrução a partir da percepção de que é preciso estar aberto a tal necessidade, sob este aspecto Morin (2000, p. 85) esclarece:

Nossa realidade não é outra senão nossa ideia da realidade. Por isso, importa não ser realista no sentido trivial (adaptar-se ao imediato), nem irre- 
alista no sentido trivial (subtrair-se às limitações da realidade); importa ser realista no sentido complexo: compreender a incerteza do real, saber que há algo possível ainda invisível no real. Isto nos mostra que é preciso saber interpretar a realidade antes de reconhecer onde está o realismo.

A categoria 'mudanças locais e globais' foi apontada com clareza por cinco dos 22 participantes, evidenciando as mudanças nas relações familiares, sociais e com o conhecimento. Sobre este aspecto se faz oportuno salientar as reflexões moranianas de que é necessário "aprender a enfrentar a incerteza, já que vivemos em uma época de mudanças em que os valores são ambivalentes, em que tudo é ligado", dessa maneira o professor deve entender que a educação do presente e do futuro devem "se voltar para as incertezas ligadas ao conhecimento" (MORIN, 2000, p. 84). Destacaram também que há um novo aluno em suas salas de aula. Porém, há um desencontro entre o perfil desse aluno e o que lhes é oferecido no processo educativo, podendo ser identificado no relato dos participantes a seguir:

Nas últimas décadas tivemos grandes mudança tanto com o avanço tecnológico, como também nos lares, pais mais ocupados com o trabalho que cada vez exige mais dos profissionais, esse novo formato de sociedade tem gerado grandes problemas nas escolas, conflitos, falta de respeito, crianças sem limites e muitas vezes não sabendo lidar com as negativas, e o professor precisa gerenciar todas estas questões, além do grande avanço tecnológico que por sua vez traz aos alunos respostas rápidas, acesso a vários conteúdos ao mesmo tempo, e hoje eles tem essa necessidade do imediatismo, é tudo pra já. (P.20)

São tantos os acontecimentos nos dias de hoje, que é bem possível, que ao termos esse novo modelo ajustado e consolidado, tenhamos que repensar novamente, pois os alunos não serão mais os mesmos, os professores não serão mais os mesmos, a sociedade não será mais a mesma. E daí a total pertinência de ter que saber enfrentar as incertezas. (P4)

A categoria 'professor contemporâneo' foi mencionada por três dos 22 participantes com destaque para o seu novo papel diante dos elementos do contexto atual. Os participantes destacaram 
a urgência do professor perceber a necessidade de estar aberto às mudanças assim como atualizar a sua leitura de mundo constantemente como forma de renovar a sua prática em benefício do aluno que o espera na sala de aula, como destacado a seguir:

\begin{abstract}
[...] Apesar das incertezas, temos de estar constantemente alertas para a direção em que caminha o mundo, para caminharmos juntos e providenciarmos o máximo de ferramentas necessárias à realização pessoal/profissional de nossos alunos. (P.19)

[...] precisa estar aberto a essas mudanças e entrelaçar aprendizagem na escola com a tecnologia, instigá-los a refletir, ser mais dinâmicos e levar esses alunos a serem críticos que consigam resolver seus próprios conflitos para serem pessoas mais preparadas para o seu futuro. (P.20)
\end{abstract}

Identifica-se nos relatos anteriores que os professores falam sobre a necessidade da superação de alguns pensamentos, de "certezas doutrinárias, dogmáticas e intolerantes que se encontram as piores ilusões", substituindo-as pela "consciência do caráter incerto do ato cognitivo constitui a oportunidade de chegar ao conhecimento pertinente, o que pede exames, verificações e convergência dos indícios" (MORIN, 2000, p. 86), as reflexões dos participantes apontam que os professores têm pensado sobre renovação da prática pedagógica com a finalidade de contribuir efetivamente no desenvolvimento do estudante.

A categoria "percepção sobre o aluno" foi destacada pelos participantes que revelaram a preocupação com os desafios a serem vencidos pelos alunos indicando também aspectos que o professor precisa considerar para poder ajudá-los, essa percepção se encaixa na ideia de Morin (2000, p. 39) quando afirma que "a compreensão dos dados particulares também necessita da ativação da inteligência geral, que opera e organiza a mobilização dos conhecimentos de conjunto em cada caso particular. Neste sentido, a articulação das produções a seguir mostra a importância de aprender e ensinar a lidar com a incerteza, segundo os professores participantes: 
[...] Aluno, não importa a idade, necessita ser estimulado, instigado e desafiado para que se interesse pelo assunto. Percebo que o problema não é o conteúdo, porque todos têm interesse em aprender o que consideram útil para a sua sobrevivência, isso é instintivo, sendo assim, a abordagem deve ser priorizada, a forma como a informação é intermediada ao aluno. (P8) [...] O que sinto é que muitos de nossos alunos estão desinteressados por muitas coisas, alguns comparecem a escola só para fazer um social, digamos assim, não se interessam por nada do ambiente escolar, do aprendizado. Não querem participar das aulas, das atividades. (P2)

Na continuidade da análise optou-se por trazer as ideias dos participantes na categoria denominada 'contribuições para a reforma da prática pedagógica', na qual são elencados alguns princípios que buscam superar pensamentos e ações fechados, por ideias que promovam "ensinar os métodos que permitam estabelecer as relações mútuas e as influências recíprocas entre as partes e o todo em um mundo complexo" (MORIN, 2000, p. 14). Para melhor apresentação desses dados foi elaborado um quadro 1 que apresenta as contribuições dos participantes.

Assim, perceber a incerteza em suas diferentes modalidades na realidade humana se mostra urgente duplamente. De um lado o professor que se debate em um contexto múltiplo sendo desafiado a todo instante pelo aluno com perfil muito diverso do que ele acreditava encontrar, o aluno não se reconhecendo no ambiente de aprendizagem, contestando-o a todo instante sem perceber que aprender é essencial para ele e suas escolhas no momento e em futuro breve, entre outros aspectos que poderão ser tratados em outro estudo.

\section{Considerações finais}

Diante da realidade em constante transformação em função da presença da tecnologia em todos os setores da vida humana, porém com seus atores ainda agindo com base no mundo construído a partir dos pressupostos da ciência clássica, percebe-se, de modo especial na educação, a necessidade urgente de refletir a respeito da prática pedagógica necessária para o contexto atual. 


\section{Quadro 1 -Subcategorias da categoria Contribuições para a reforma da prática pedagógica}

\begin{tabular}{|c|c|}
\hline Sub- categoria & Relatos dos participantes \\
\hline $\begin{array}{l}\text { Metodologia } \\
\text { projetos }\end{array}$ & $\begin{array}{l}\text { Propor práticas pedagógicas que envolvam ações e proje- } \\
\text { tos no tema sustentabilidade e relacionados a outras causas } \\
\text { voltadas à melhoria do mundo, que gerem engajamento e } \\
\text { educação para a cidadania, podem ser um caminho para o } \\
\text { desenvolvimento integral dos estudantes. (P16). } \\
\text { Mudança educacional tem que acontecer sim, propondo } \\
\text { práticas pedagógicas que envolvam ações e projetos e que } \\
\text { gerem um engajamento maior e mais consciente desses } \\
\text { adolescentes. (P2) }\end{array}$ \\
\hline $\begin{array}{l}\text { Aprender } \\
\text { fazendo }\end{array}$ & $\begin{array}{l}\text { Quando os alunos experienciam a arte e magia de construir } \\
\text { o seu conhecimento tudo faz mais sentido, tudo é mais in- } \\
\text { teressante. Quando isto acontece, quando por via da expe- } \\
\text { rimentação o aluno vai testando, falhando e testando outra } \\
\text { vez até perceber a lógica e compreender os conceitos, o } \\
\text { aluno coloca-se no papel do cientista que há } 2 \text { séculos che- } \\
\text { gou à mesma conclusão. (P1) }\end{array}$ \\
\hline Contextualização & $\begin{array}{l}\text { A mudança pedagógica que estamos vivenciando foca num } \\
\text { ensino construtivistas, que pretende priorizar a aprendiza- } \\
\text { gem a partir da contextualização dos conteúdos e discipli- } \\
\text { nas com a realidade e a fazendo com os estudantes bus- } \\
\text { quem as diversas soluções para as situações e problemas } \\
\text { apresentados. (P4). }\end{array}$ \\
\hline Diálogo & $\begin{array}{l}\text { Emerge a necessidade de nos despirmos de todas as con- } \\
\text { cepções tradicionais que temos da Escola e do Ensino. } \\
\text { Hoje temos que reinventar estratégias e pensar o ato edu- } \\
\text { cativo como um momento em que professor, aluno e saber } \\
\text { dialogam no mesmo espaço e em que nenhum destes pila- } \\
\text { res se sobrepõe aos outros (P1) }\end{array}$ \\
\hline Tecnologia & $\begin{array}{l}\text { Quanto às tecnologias o professor deve estar sempre prepa- } \\
\text { rado para lidar com as inovações, pois esta deve ser usada a } \\
\text { nosso favor, podendo ser o meio de despertar a vontade de } \\
\text { aprender dos nossos alunos. (P7) } \\
\text { Horários flexíveis, conteúdos dinâmicos e sempre disponí- } \\
\text { veis, interação educacional são alguns exemplos de possibi- } \\
\text { lidade. Como educadores, podemos incentivar a utilização } \\
\text { tecnológica como auxiliar na evolução do conhecimento e } \\
\text { do sabe. (P15) }\end{array}$ \\
\hline $\begin{array}{l}\text { Planejamento } \\
\text { flexível }\end{array}$ & $\begin{array}{l}\text { A própria sala de aula, por ser um recorte da realidade, nos } \\
\text { mostra sua complexidade. É daí que afirmo o seu caráter } \\
\text { imprevisível, isto é, das relações que ali também se estabele- } \\
\text { cem. Neste sentido, o professor deve sempre planejar suas } \\
\text { aulas de maneira flexível. (P10). }\end{array}$ \\
\hline
\end{tabular}

Fonte: as autoras, 2020. 
Retomando o problema dessa investigação que fez a seguinte indagação: De que forma podemos inserir os construtos dos sete saberes, especificamente do saber da incerteza como base epistemológica para a prática pedagógica docente contribuindo com os desafios impostos para a educação na contemporaneidade?, pode-se levantar as principais considerações a respeito da análise, destacando que os participantes reconhecem a incerteza como um dos elementos do contexto em que estão inseridos, bem como a urgência da reflexão sobre a prática pedagógica buscando colocar-se de forma disponível para a mudança. Identificam também que há um novo aluno em suas salas de aula que, na maioria das vezes, não se sente pertencente ao mundo da sala de aula proposta por seu professor e por sua escola. Sendo assim, precisam ser revistos tanto o papel do professor na sala de aula, quanto o do aluno. Mas, a ênfase das contribuições encontra-se na urgência de buscar a transformação da prática pedagógica que leve a produção de conhecimento, ao mesmo tempo incluir os estudantes com suas diferentes manifestações e características.

Nesse movimento, as manifestações dos participantes permitem perceber que o aluno necessita ser instigado a reconhecer sobre a emergência de enfrentar as incertezas, a investigar problemas da sua realidade, considerar o contexto atual e nele agir com eficiência. Nota-se, portanto, a importância de reconstruir a visão de mundo tanto do aluno como do professor em direção à superação da visão reducionista. Enfatizam a pertinência de considerar a visão da complexidade presente na realidade a qual permite vislumbrar estratégias que possibilitem a formação integral e humana tanto do aluno como do professor. E nesse sentido, se mostra indispensável considerar e enfrentar a incerteza traduzida no imprevisto, no aleatório, no funcionamento imprevisível da mente humana.

A resposta ao problema de pesquisa inclui o reconhecimento da necessidade de mudança da visão de mundo, o abrir-se ao processo de transformação ao qual todos estão submetidos e a reflexão a respeito da sua prática pedagógica e possíveis transformações. 
Como continuidade dessa pesquisa pode-se vislumbrar o estudo da inserção da incerteza para construir processos formativos que possibilitem a educação do indivíduo em sua multiplicidade de dimensões.

\section{Referêmcias}

BOGDAN, Robert; BIKLEN, Sari. Investigação qualitativa em educação. Tradução de Maria João Alvarez, Sara Bahia dos Santos e Telmo Mourinho Baptista. Porto: Porto, 1994.

DELORS, Jacques. Educação: um tesouro a descobrir. 1. ed. São Paulo: Cortez; MEC-UNESCO, 1996.

FERRO, Ana Paula Rodrigues. A netnografia como metodologia de pesquisa: um recurso possível. Educação, Gestão e Sociedade: revista da Faculdade Eça de Queirós, Ano 5, número 19, agosto de 2015. Disponível em: http://uniesp.edu. br/sites/_biblioteca/revistas/20170509161801.pdf. Acesso em: 13/03/2020.

MORIN, Edgar. Ciência com consciência. Tradução de Maria D. Alexandre e Maria Alice Sampaio Dória. 3. ed. Rio de Janeiro: Bertrand Brasil, 1999.

MORIN, Edgar. Os sete saberes necessários à educação do futuro. Tradução de Catarina E. F. da Silva e Jeanne Sawaya. São Paulo: Cortez; Brasília, DF: UNES$\mathrm{CO}, 2000$.

MORIN, Edgar. O método I: a natureza da natureza. 3.ed. Tradução de Maria Gabriela de Bragança. Lisboa: Publicações Euro-América, 1997.

MORIN, Edgar; KERN, Anne Brigitte. Terra-Pátria. 2 ed. Lisboa: Instituto Piaget, 2001.

MORIN, Edgar. Os sete saberes necessários à educação do presente. In: MORAES, Maria Cândida; ALMEIDA, Maria Conceição de. (orgs). Os sete saberes necessários à Educação do presente: por uma educação transformadora. Rio de Janeiro: Wak, 2012.

MORIN, Edgar. Introdução ao Pensamento Complexo. Tradução de Dulce Matos. $2^{a}$ ed. Lisboa: Instituto Jean Piaget, 1990.

NICOLESCU, Basarab. O manifesto da transdisciplinaridade. Tradução de Lúcia Pereira de Souza. São Paulo: TRIOM, 1999. 
PENA-VEGA, Alfredo; ALMEIDA, Cleide R. S.; PETRAGLIA, Izabel (orgs). Edgar Morin: ética, cultura e educação. 2.ed. São Paulo: Cortez, 2003.

PETRAGLIA, Izabel. “Olhar sobre o olhar que olha”: complexidade, holística e educação. Petrópolis: Vozes, 2001.

THIOLLENT, M. Metodologia da pesquisa-ação. 18. ed. São Paulo: Cortez, 2011.

PEFOP. PARADIGMAS EDUCACIONAIS NA FORMAÇÃO DE PROFESSORES. Grupo de pesquisa PEFOP. Pontifícia Universidade Católica do Paraná. Curso online Formação de Professores para uma Prática Inovadora. Sete saberes necessário para educação do futuro. Disponível https://www.pefop.com. br/divulgacao-formacao-de-professores-para-uma-pratica-inovadora/ consultado em 06.03.20. 